\section{- Poster 7}

TITLE: Use of miniinplants for stabilization of totally mandibular dentures in geriatric patients

\author{
AUTHORS: Gómez Palomo FJ, Gil Gonzalez J, Al- \\ Adib Mendiri A, Jiménez Guerra A, Ortiz García I, \\ Velasco-Ortega E. \\ Máster de Implantología Oral, Facultad de Odontología, Universi- \\ dad de Sevilla.
}

SOURCE: Med Oral Patol Oral Cir Bucal. 2016 December 15;21(Supplement1):S36.

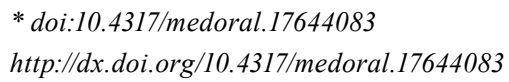

* doi:10.4317/medoral.17644083

http://dx.doi.org/10.4317/medoral.17644083

Today, totally edentulism in older patients is delayed due to oral prevention. However, in the elderly, the physiological state reduces patient's ability to adapt to oral rehabilitation and gets worse the patient's oral control. Consequently, elderly edentulous subjects avoid many types of foods which can lead to substantial nutritional consequences. Actually, the treatment of reference in prosthodontic mandibular rehabilitation are complete dentures retained by implants. In fact, the symphyseal region generally allows implant treatment even when the mandibles are strongly resorbed. However, in geriatrics patients, a complex surgical procedure and its consequences could compromise standard implant rehabilitation. In addition, the high cost of implant use can be an additional barrier. In this context, the use of geriatric minimplants could be an interesting treatment option. The surgical procedure was found to be less invasive, less expensive, and more simple than the conventional procedure. This protocol could be used systematically to treat full edentulism in geriatric patients. Long-term monitoring and the evaluation of the reliability of this type of rehabilitation should be undertaken.

\section{- Poster 8 \\ TITLE: Dental implants in patients with osteo- porosis}

AUTHORS: González García C, Bish González MJ, Rondón Romero JL, Jiménez Guerra A, Ortiz García I, Velasco-Ortega E.

Máster de Implantología Oral. Facultad de Odontología. Universidad de Sevilla.

SOURCE: Med Oral Patol Oral Cir Bucal. 2016 December 15;21(Supplement1):S36.

*doi:10.4317/medoral.17644084

http://dx.doi.org/10.4317/medoral.17644084
Life expectancy has increased considerably over the past 40 years due to the advance in medicine. Therefore, increasing the amount of elderly patients which demand an improvement in their quality of life as well as their oral health. Many of them request the possibility of restoring their dentition with osseointegrated implants and, in such cases, the advance age will not be and impediment for such treatment. The treatment success depends on the overall health status and good oral health of the patient. It is critical to have a complete comprehensive examination and treatment plan accordingly to the needs of the patient. The wide range of pathological situations that elderly people usually manifest, make us modify the implant rehabilitation planning, but currently, there is a reduced number of definitive contraindications. Numerous diseases can affect the bone metabolism such as, osteoporosis, specifically in postmenopausal women, oncologic patients, Paget disease, hormonal disturbance and drug adverse effects. As a consequence of all of these pathologies, the bone density and micro architectural bone structure have been seriously affected and will represent an important risk factor in our treatment planning. The presence of some of these pathologies can be even more dangerous when the patient has been or is still being treated with bisphosphonates. This might be one of the most risky situations that the provider might encounter. Even though bisphosphonates are not an absolute contraindication, this type of medication presents certain characteristics that could derivate into osteonecrosis of the jaw bone. Recent published studies showed favorable results regarding bone formation around dental implants in patients with osteoporosis. There was no difference between dental implants in normal bone and dental implants in osteoporotic bone.

\section{- Poster 9}

TITLE: Immediate loading in the treatment with implants of the geriatric patient

AUTHORS: González Suarez S, González Suarez V, Rondón Romero JL, Moreno Muñoz J, Nuñez Marquez E, Velasco Ortega E.

Máster de Implantología Oral. Facultad de Odontología. Universidad de Sevilla.

SOURCE: Med Oral Patol Oral Cir Bucal. 2016 December 15;21(Supplement1):S36.

*doi:10.4317/medoral.17644085

http://dx.doi.org/10.4317/medoral.17644085

Over the years, there have been major advances in the field of dentistry, because of the increased in life expectancy of patients, which has increased the demand for treatments aimed at improving the quality of geriatric 
population life. Oral implantology allows us the rehabilitation of edentulous patient fixed, without resorting to conventional treatments of removable prostheses, which affect it in terms of function, aesthetic and psychology. At first, this type of technique required a certain period of osseointegration and stability of implants, which increased the delay in the placement of prosthetic rehabilitation. However, new protocols have been developed in order to simplify the surgical and prostheses phases, providing the patient with an immediate, definite and less traumatic solution with predictable results. Nowadays, one of the most used methods is the immediate loading of implants, which allows us to place them in the same surgical act and in turn the restoration. In order to get a feasible procedure, we must consider the individual characteristics of each patient, as well as the rehabilitation we have planned to perform at the same.

\section{- Poster 10}

TITLE: Use of zygomatic implants for rehabilitation of atrophic jaws in elderly patients

AUTHORS: González Suarez V, González Suarez S, Reche Ibañez A, España López A, Matos Garrido N, Velasco Ortega E.

Máster de Implantología Oral. Facultad de Odontología. Universidad de Sevilla.

SOURCE: Med Oral Patol Oral Cir Bucal. 2016 December 15;21(Supplement1):S37.

* doi:10.4317/medoral.17644086

http://dx.doi.org/10.4317/medoral.17644086

Oral implantology has become one of de most important fields in dentistry in recent years, allowing partial and totally rehabilitation of edentulous patient. In geriatric patients, as a result of aging and progressive tooth loss, al the same time occurs an alveolar bone resorption that sometimes difficult us to place the implants in the ideal position for the subsequent prosthetic rehabilitation. This forces us to employ techniques of bone regeneration or maxillary sinus lifts, which involve certain risks in terms of systemic pathology and medication to the patient. Nowadays they are developing other therapeutic alternatives in order to avoid the techniques previously referred, decreasing morbidity and promoting acceptance of implant treatment by the patient. Use of zygomatic implants is one of the most used procedures, showing a high rate of success and considerate a safe and predictable technique. Even so, it has a number of disadvantages because it is a complex procedure involving a important number of anatomical structures and requires a previous surgical experience.

\section{- Poster 11}

TITLE: All-on-Four as a treatment option for geriatric edentulous patients

AUTHORS: Miralles Cruceira M, Perez Gonzalez ME, Rubio Urbano A, España López A, Matos Garrido $\mathbf{N}$, Velasco Ortega $\mathrm{E}$.

Máster de Implantología Oral. Facultad de Odontología. Universidad de Sevilla.

SOURCE: Med Oral Patol Oral Cir Bucal. 2016 December 15;21(Supplement1):S37.

* doi:10.4317/medoral.17644087

http://dx.doi.org/10.4317/medoral.17644087

The oral cavity influences the overall health of the elderly, from language and chewing up the physical appearance and self-esteem. Edentulism is one of the main problems of geriatric patients. With tooth loss accompanied by severe bone resorption, is difficult rehabilitation with implants in atrophic jaws. The introduction of the concept and protocol of All-on-four can offer to geriatric patients the possibility of a fixed prosthesis on four implants the same day intervention. Immediate loading of four implants, two conventional and two tilded implants for avoid anatomical structures (maxilary sinus, foramina) in the treatment of edentulous maxilla or mandible constitute a dental treatment with a high success rate success. So is achieved immediately, increase patient satisfaction including functionality, perception and aesthetics.

\section{- Poster 12}

TITLE: Implant-Retained Removable Partial Dentures. An alternative therapy in elderly patients

AUTHORS: Monje Iñigo MM, Miralles Cruceira M, Reche Ibañez A, Matos Garrido N, Ortiz García I, Velasco Ortega E.

Máster de Implantología Oral. Facultad de Odontología. Universidad de Sevilla.

SOURCE: Med Oral Patol Oral Cir Bucal. 2016 December 15;21(Supplement1):S37.

* doi:10.4317/medoral.17644088

http://dx.doi.org/10.4317/medoral.17644088

Today, partial dentures remain one of the choices made by elderly patients. There are certain drawbacks of such prostheses though, mainly due to the misfit appearing with time which causes certain rotation on the free ends. This brings about discomfort that affects mastication, phonation and patient self-confidence. Inserting 